\title{
50V All-PMOS Charge Pumps Using Low-Voltage Capacitors
}

\author{
Ahmed Emira, Senior Member, IEEE, Mohamed AbdelGhany, Student Member, IEEE, Mohannad Elsayed,
} Student Member, IEEE, Amro Elshurafa, Member, IEEE, Sherif Sedky, Khaled Salama, Senior Member, IEEE

\begin{abstract}
In this work, two high-voltage charge pumps are introduced. In order to minimize the area of the pumping capacitors, which dominates the overall area of the charge pump, high density capacitors have been utilized. Nonetheless, these high density capacitors suffer from low breakdown voltage which is not compatible with the targeted high voltage application. To circumvent the breakdown limitation, a special clocking scheme is used to limit the maximum voltage across any pumping capacitor. The two charge pump circuits were fabricated in a $0.6 \mu \mathrm{m}$ CMOS technology with poly0-poly1 capacitors. The output voltage of the two charge pumps reached $42.8 \mathrm{~V}$ and $51 \mathrm{~V}$ while the voltage across any capacitor did not exceed the value of the input voltage. Compared to other designs reported in the literature, the proposed charge pump provides the highest output voltage which makes it more suitable for tuning MEMS devices.
\end{abstract}

Index Terms-Charge pump, high voltage, MEMS interface, polarization voltage, DC-DC converters

\section{INTRODUCTION}

D ESPITE the continuous demand for reducing the supply voltage and the power consumption of integrated circuits $[1,2]$, there are some applications that still require high voltage operation, such as MEMS devices, EEPROM programmers [38], power switches [9], LCD and line drivers [10]. To meet the high voltage requirement, capacitive charge pumps are used in light load applications, while step-up DC-DC converters are used in heavy load applications [11-17]. Most of charge pump (CP) topologies in the literature $[2,18-20]$ are based on the Dickson charge pump [21], which is shown in Fig. 1, where the output voltage is given by:

$$
V_{O U T}=(N+1) V_{I N}-V_{t 1}-V_{t 2}-\cdots-V_{t N}-V_{t o}
$$

where $N$ is the number of stages, $V_{I N}$ is the input voltage, and $V_{t i}$ and $V_{t o}$ are the threshold voltages of the $i^{\text {th }}$ stage (where $i=1,2, \cdots, N$ ) and the output stage, respectively. This architecture suffers from the continuous increase in the threshold voltage from stage to stage due to the increase in the bulk-source voltage of $M_{i}$ transistor as $i$ increases. Furthermore, the maximum attainable output voltage is limited by

Copyright (c) 2009 IEEE. Personal use of this material is permitted. However, permission to use this material for any other purposes must be obtained from the IEEE by sending a request to pubs-permissions@ieee.org.

A. Emira, M. AbdelGhany, and M. Elsayed are with the Electronics and Communications Department, Faculty of Engineering, Cairo University, Giza, Egypt.

A. Elshurafa and K. Salama are with King Abdullah University of Science and Technology, Thuwal, Saudi Arabia.

S. Sedky is with Zewail University, Cairo, Egypt.

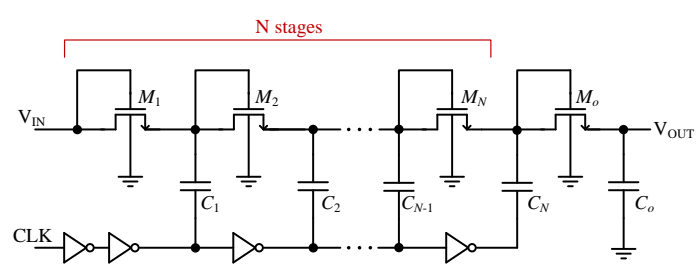

Figure 1. Dickson charge pump.

the breakdown voltages of the diode connected transistors and the pumping capacitors, $C_{i}$. For example, maximum voltage across the capacitor $C_{N}$ in the last stage is $V_{O U T}-V_{I N}-V_{t o}$.

The threshold voltage drop in each stage of the charge pump limits use of the Dickson CP in practice. Several solutions were suggested in the literature to solve this problem. The topology used in [3] employs a bootstrap circuit to obtain the high voltage required to turn $\mathrm{ON}$ the charge transfer switches in the triode region, and hence avoid the threshold voltage drop. The series-parallel topology was originally suggested in [22] for discrete implementation. IC implementation of this topology is limited due to its higher power losses as a result of the high voltage swing on the parasitic capacitances [20]. More complex clocking schemes are also used to eliminate the body effect. In [18, 23], a double branch pumping architecture is used with a 6-phase clocking scheme. A combination of both forward and backward control schemes are used in[24].

High voltage CPs are usually implemented using special high-voltage technologies as in [19, 25-27]. While [28] used a high-voltage clock generator to build a charge pump with an output voltage that is linear with the number of stages. In addition, [29] used a high voltage CMOS/DMOS process to achieve high density and high output voltage charge pumps, and finally, [30] used a double charge pumping circuit with a 4-phase clocking scheme. A standard CMOS process was used in the charge pump proposed in [31] and [32], but the output voltage is limited to only $18 \mathrm{~V}$ and $8.8 \mathrm{~V}$, respectively. A high current charge pump is presented in [27] which generates a $9 \mathrm{~V}$ output using high voltage CMOS technology.

In this work, a variable-output high-voltage charge pump has been designed and simulated using a $0.6 \mu \mathrm{m}$ CMOS process and particular attention has been dedicated for MEMS gyroscope applications. In contrary to previous published designs, this design does not utilize any high-voltage capacitors in the charge pump core $[25,26,29,30,33]$. Instead, a special clocking scheme is used, in which each stage takes the input clocks from the previous stage and generates the output clocks 
with a DC offset. As a result, the maximum voltage across the pumping capacitors is only $V_{I N}$ for all stages. A two-port model of the proposed charge pump has been derived and power efficiency has been obtained in terms of the parasitic capacitors and number of stages.

The paper is organized as follows; section II shows the charge pump architecture and principle of operation. Section III presents the charge pump analysis and the two port model. Finally, simulation results are presented in section V.

\section{Proposed Charge Pump}

The circuit architecture of the basic high-voltage all-PMOS series-capacitor charge pump (SCCP) using low-voltage capacitors is shown in Fig. 2. The circuits is based on the Cockcroft-Walton (CW) voltage multiplier [22]. The wellknown problem of sensitivity of $\mathrm{CW}$ voltage multiplier to parasitic capacitances of the pumping capacitors has limited its use in integrated circuits. Such a problem is addressed in section III and a proposed solution is presented in section IV. Note that the gate voltage waveforms of the PMOS transistors $M_{i A}$ and $M_{i B}$ are expressed in terms of $V_{S L}$ and $V_{S H}$. The output of each stage is used as the pumping clock for the next stage. The operation of the proposed charge pump can be described, assuming zero load current and no parasitics capacitances, as follows: when $C L K=0$ and $C L K_{b}=V_{I N}$, transistors $M_{1 A}$ and $M_{1 B}$ turn $\mathrm{OFF}$ and $\mathrm{ON}$, respectively. Then $V_{1 O P}=V_{I N}-\delta$, where $\delta$ is the voltage drop across the PMOS switch $M_{1 B}$. The value of $\delta$ depends on region of operation of the PMOS switch when it is turned ON. A necessary condition for zero voltage drop $(\delta=0)$ at zero load current, is to force the PMOS transistor to operate in the ohmic region, then

$$
V_{S L}<V_{I N}-V_{T}
$$

On the other hand, to make sure than $M_{1 A}$ is turned OFF, then

$$
V_{S H}>2 V_{I N}-\delta-V_{T}
$$

Note that the required voltage swing at the gates of the PMOS transistors to obtain $\delta=0$ is larger than $V_{I N}$. Transistors $M_{i C}$ and $M_{i D}$ are used to connect the bulks of transistors $M_{i A}$ and $M_{i B}$ to the maximum of the two output votlages $V_{i O P}$ and $V_{i O N}$, which is $(i+1) V_{I N}-i \delta$, to avoid turning ON the bulk-source or bulk-drain diodes of these transistors. The voltage gain in each stage is $V_{I N}-\delta$, except for the last stage where the voltage gain is $V_{I N}$. The overall open-circuit voltage gain of the proposed charge pump is expressed as:

$$
V_{O U T}=(N+1) V_{I N}-N \delta
$$

The main advantage of the proposed architecture is that the voltage drop across any pumping capacitor does not exceed $V_{I N}-\delta$. Hence, integrated low voltage capacitors can be used. However, the output capacitor which is used to smoothen the output voltage if needed, still sees the full output voltage. This is not an issue since this output is typically connected to a pin (to be connected to the gyroscope tuning terminal) where a small off-chip capacitor can be used. In
MEMS gyroscopes, polarization voltages are used to tune the resonance frequencies of the drive and/or sense modes for matching purposes [34]. Moreover, it is desired to program the polarization voltage over a large operation range from a few volts up to $40 \mathrm{~V}$ or higher [35].

Depending on how the gate voltages of the PMOS transistors, $M_{i A}$ and $M_{i B}$, are generated, two charge pump circuit architectures are proposed in the following subsections.

\section{A. SCCP with Diode-Connected Switches (SCCP-DCS)}

In the SCCP-DCS, the gate voltages of $M_{i A}$ and $M_{i B}$ are connected to the output votlages, $V_{i O N}$ and $V_{i O P}$, of the $i^{t h}$ stage, respectively. This diode connection results in violating condition (2) which gives rise to a voltage loss $\delta=V_{T}$ in each stage, except for the last one. Condition (3), however, is still met since $V_{S H}=2 V_{I N}-V_{T}$. Depsite the voltage loss, the circuits offers no more complexity (no extra transistors) other than what is shown in Fig. 2.

\section{B. SCCP with Ohmic Switches (SCCP-OS)}

In order to obtain zero open-circuit voltage drop $(\delta=0)$ in each stage, the voltage swing at the gates of the PMOS transistors must be set higher than $V_{I N}$. To do this, a clock level shifting circuit composed by $M_{1 E}, M_{1 F}, M_{1 G}$, and $M_{1 H}$, is used in the first stage to generate differential clocks with 0 to $2 V_{I N}$ swing. This high swing clock is used to drive the PMOS switches of the first stage. It is also used to drive the level shifting circuits of the second stage, composed by transistors $M_{2 E}$ and $M_{2 F}$, and capacitors $C_{2 C}$ and $C_{2 D}$. The second stage level shifter generates differential output clocks with $V_{I N}$ to $3 V_{I N}$ swing which are suitable for driving the second stage charge pump and the third stage level shifters, and so on. These clock levels can be translated to $V_{S L}=0$ and $V_{S H}=2 V_{I N}$ which satisfy conditions (2) and (3), respectively. The voltage across the clock level shifting capacitors $C_{i C}$ and $C_{i D}$ is limited to $V_{I N}$ and low voltage capacitors can be utilized.

The use of normal NMOS transistors in the Dickson charge pump forces the bulk terminals of the different transistors to be connected to ground. As a result, the body effect causes the threshold voltage of the NMOS transistor to increase from stage to stage. At some point, when $V_{t N}$ becomes higher than $V_{I N}$, the output voltage starts decreasing as $N$ increases and this point represents the maximum attainable output voltage for this specific circuit architecture. With the latter in mind, PMOS transistors were utilized as the switching pair because the bulk of each transistor can be connected separately. However, the bulk of the PMOS transistor cannot be connected directly to the source because the source voltage is higher than the drain voltage in one clock phase and lower in the other. This problem has been solved in our proposed $\mathrm{N}$-stage charge pump shown in Fig. 3 by using transistors $M_{i G}$ and $M_{i H}$. Explicitly, transistors $M_{i G}$ and $M_{i H}$ select the maximum of the two output voltages of the $i^{\text {th }}$ stage (which is equal to $\left.(i+1) V_{I N}\right)$ and connect it to the bulk of the PMOS transistors in this stage. The gates of the transistors 


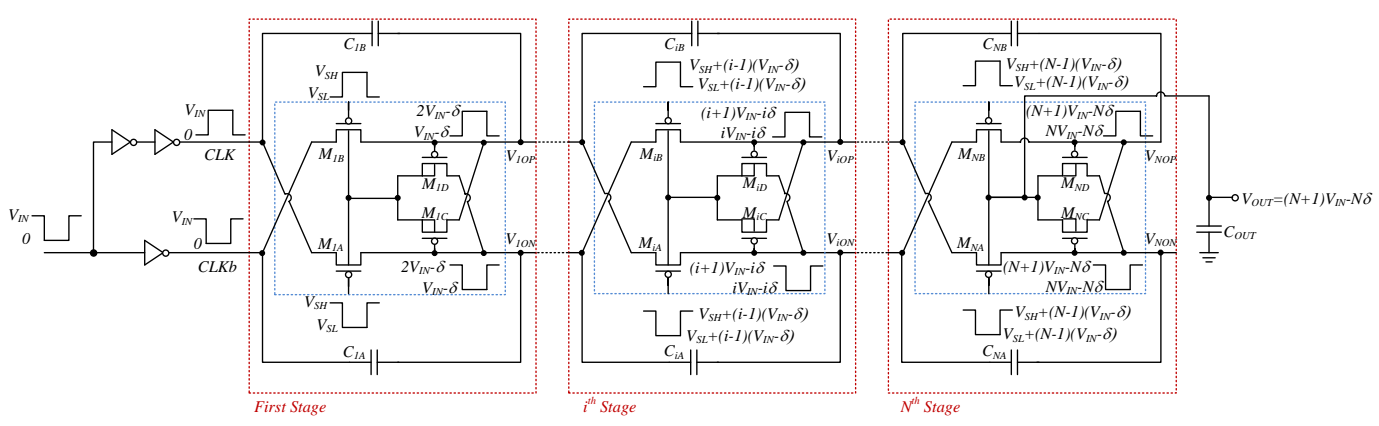

Figure 2. Proposed basic charge pump architecture.

$M_{i C}, M_{i D}, M_{i E}$, and $M_{i F}$ are biased at $i V_{I N}$ (obtained from the $(i-1)^{t h}$ stage). When $V_{(i-1) O P}$ is low at $(i-1) V_{I N}$ and $V_{i O P}$ is low at $i V_{I N}$, then $M_{i D}$ turns ON and $M_{i F}$ turns OFF. Therefore, the gate of $M_{i B}$ is set to $(i-1) V_{I N}$ to turn it ON and connect $V_{(i-1) O N}$ to $V_{i O P}$. When $V_{(i-1) O P}$ is high at $i V_{I N}$ and $V_{i-O N}$ is high at $(i+1) V_{I N}$, then $M_{i D}$ turns OFF and $M_{i F}$ turns ON. In this case, the gate of $M_{i B}$ is set to $(i+1) V_{I N}$ to turn it OFF. Therefore, the swing at the gate of $M_{i B}$ is $2 V_{I N}$ (from $(i-1) V_{I N}$ to $(i+1) V_{I N}$ ) which is needed to eliminate the body effect. The same rationale can be applied for the swing at the gate of transistor $M_{i-2}$ of the $i^{t h}$ stage.

Using such a technique, the maximum voltage across any transistor is $2 V_{I N}$, while the maximum PMOS body voltage occurs in the $N^{t h}$ stage and is equal to $V_{O U T}$. However, this is not an issue since the breakdown voltage of n-well to psubstrate in CMOS technology we used is $70 \mathrm{~V}$. The nwell. and the maximum voltage across any capacitor (except for $C_{O U T}$ ) is $V_{I N}$, regardless of the number of stages. The output voltage for $N$-stage charge pump, ignoring parasitic capacitors, can be expressed as:

$$
V_{\text {OUT }}=(N+1) V_{I N}
$$

By limiting the maximum voltage across the pumping capacitors, $C_{i A}$ and $C_{i B}$, we allow using low-voltage and highdensity capacitors. Hence, we minimize the overall charge pump area which is dominated by these capacitors. However, the output capacitor, $C_{O U T}$, still sees the entire output voltage and thus a high-voltage capacitor must be used. Since the charge pump output is usually connected to a pin (to be connected to a MEMS gyroscope), an external capacitor can be used for $C_{O U T}$.

\section{Charge Pump Analysis}

So far, we have ignored the parasitic capacitance of the pumping capacitors and the switching transistors. Such parasitic capacitances cause power loss and hence reduction in the output voltage[36]. To obtain a linearized model of the proposed charge pump, we will find expressions for the open circuit output voltage and output impedance. In this analysis, we assume that the switch turns $\mathrm{ON}$ in ohmic region (e.g. as in the SCCP-OS) with a resistance, $R_{S}$, which is negligible compared to the pumping capacitors impedance at the switching frequency. In other words, we use the following assumption:

$$
\frac{1}{2 \pi R_{S} C} \gg f_{C L K}
$$

The connections of the pumping capacitors in the two phases $\phi_{1}\left(C L K=V_{D D}\right)$ and $\phi_{2}(C L K=0)$ are shown in Fig. 4. To take the effect of parasitic capacitors into account, each pumping capacitor is modeled as a floating capacitance, $C$, and a grounded parasitic capacitance, $C_{S}=\alpha C$, which represents the parasitic capacitor from the bottom plate to ground; where $\alpha$ is the ratio between the bottom plate parasitic capacitance and the floating capacitance. From the connections in Fig. 4(a), we can write the following equations:

$$
\begin{gathered}
v_{1 A}^{\phi_{1}}=V_{I N} \\
v_{i A}^{\phi_{1}}=v_{i-1 B}^{\phi_{1}} \quad \text { for } \quad i=2,3, \cdots N
\end{gathered}
$$

where $v_{i A}^{\phi_{1}}$ and $v_{i B}^{\phi_{1}}$ are the voltages at the end of phase $\phi_{1}$ across the capacitors $C_{i A}$ and $C_{i B}$, respectively. By considering charge conservation when switching from $\phi_{2}$ to $\phi_{1}$, we can write:

$$
\begin{array}{r}
v_{i B}^{\phi_{1}}=v_{i A}^{\phi_{1}}-2 v_{i+1 A}^{\phi_{1}}+v_{i+2 A}^{\phi_{1}}-\alpha v_{i B}^{\phi_{1}}+(2+\alpha) v_{i+1 B}^{\phi_{1}}-v_{i+2 B}^{\phi_{1}} \\
\text { for } \quad i=1,2, \cdots N-2 \quad(8)
\end{array}
$$

where the equations $v_{i A}^{\phi_{2}}=v_{i B}^{\phi_{1}}$ and $v_{i B}^{\phi_{2}}=v_{i A}^{\phi_{1}}$ (for $i=$ $1,2, \cdots, N)$ are used from the problem symmetry. Equation (8) is not valid for $i=N-1$ and $i=N$. The missing equations are:

$$
\begin{gathered}
v_{N-1 B}^{\phi_{1}}=v_{N-1 A}^{\phi_{1}}-v_{N A}^{\phi_{1}}-\alpha v_{N-1 B}^{\phi_{1}}+v_{N B}^{\phi_{1}}-\frac{I_{O U T}}{2 f_{c l k} C} \\
v_{N B}^{\phi_{1}}=v_{N A}^{\phi_{1}}-\frac{I_{O U T}}{2 f_{c l k} C}
\end{gathered}
$$

where it is assumed that the clock has $50 \%$ duty cycle. Equations (6-10) can be written in the following matrix form.

$$
V_{A}^{\phi_{1}}=M_{A B} V_{B}^{\phi_{1}}+K_{1} V_{I N}
$$




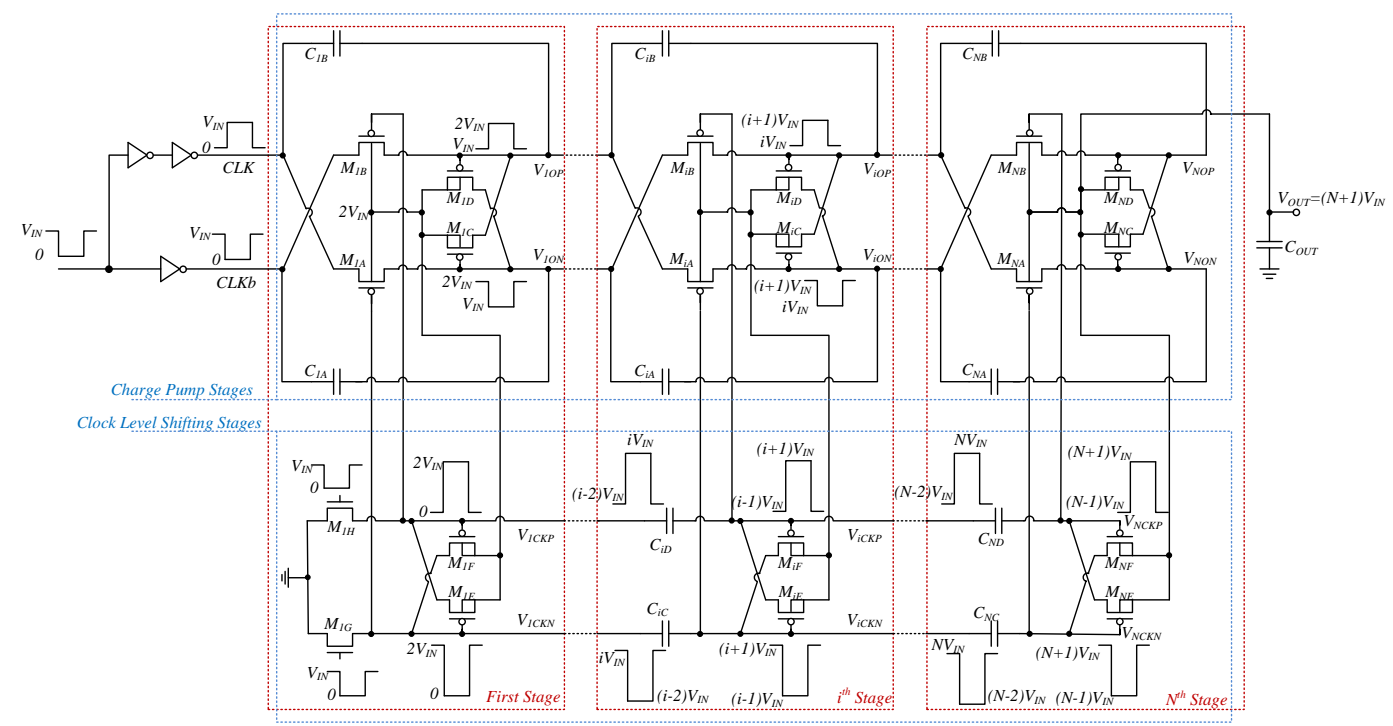

Figure 3. Proposed charge pump.

$$
V_{B}^{\phi_{1}}=M_{B A} V_{A}^{\phi_{1}}+M_{B B} V_{B}^{\phi_{1}}-K_{2} \frac{I_{O U T}}{2 f_{c l k} C}
$$

where $V_{B}^{\phi_{1}}=\left[\begin{array}{lll}v_{1 B}^{\phi_{1}} & v_{2 B}^{\phi_{1}} \cdots v_{N B}^{\phi_{1}}\end{array}\right], V_{A}^{\phi_{1}}=\left[\begin{array}{lll}v_{1 A}^{\phi_{1}} & v_{2 A}^{\phi_{1}} \cdots v_{N A}^{\phi_{1}}\end{array}\right]$, $K_{1}^{T}=\left[\begin{array}{lllll}1 & 0 & 0 & \cdots & 0\end{array}\right]$, and $K_{2}^{T}=\left[\begin{array}{llllll}0 & 0 & \cdots & 0 & 1 & 1\end{array}\right]$. The matrices $M_{A B}, M_{B A}$, and $M_{B B}$ are expressed as:

$$
\begin{aligned}
& M_{A B}=\left[\begin{array}{ccccccc}
0 & 0 & 0 & \cdots & 0 & 0 & 0 \\
1 & 0 & 0 & \cdots & 0 & 0 & 0 \\
0 & 1 & 0 & \cdots & 0 & 0 & 0 \\
\vdots & \vdots & \vdots & \ddots & \vdots & \vdots & \vdots \\
0 & 0 & 0 & \cdots & 1 & 0 & 0 \\
0 & 0 & 0 & \cdots & 0 & 1 & 0
\end{array}\right] \\
& M_{B A}=\left[\begin{array}{cccccccc}
1 & -2 & 1 & 0 & \cdots & 0 & 0 & 0 \\
0 & 1 & -2 & 1 & \cdots & 0 & 0 & 0 \\
0 & 0 & 1 & -2 & \cdots & 0 & 0 & 0 \\
\vdots & \vdots & \vdots & \vdots & \ddots & \vdots & \vdots & \vdots \\
0 & 0 & 0 & 0 & \cdots & 1 & -2 & 1 \\
0 & 0 & 0 & 0 & \cdots & 0 & 1 & -1 \\
0 & 0 & 0 & 0 & \cdots & 0 & 0 & 1
\end{array}\right] \\
& M_{B B}=\left[\begin{array}{ccccccc}
-\alpha & 2+\alpha & -1 & \cdots & 0 & 0 & 0 \\
0 & -\alpha & 2+\alpha & \cdots & 0 & 0 & 0 \\
0 & 0 & -\alpha & \cdots & 0 & 0 & 0 \\
\vdots & \vdots & \vdots & \ddots & \vdots & \vdots & \vdots \\
0 & 0 & 0 & \cdots & -\alpha & 2+\alpha & -1 \\
0 & 0 & 0 & \cdots & 0 & -\alpha & 1 \\
0 & 0 & 0 & \cdots & 0 & 0 & 0
\end{array}\right]
\end{aligned}
$$

The solution of the above matrix equations is expressed as:

$$
\begin{aligned}
V_{B}^{\phi_{1}}=\left(I-M_{B B}-\right. & \left.M_{B A} M_{A B}\right)^{-1} \\
& \left(M_{B A} K_{1} V_{I N}-K_{2} \frac{I_{O U T}}{2 f_{c l k} C}\right)
\end{aligned}
$$

where $I$ is the $N \times N$ unity matrix. The output voltage of the charge pump at the end of $\phi_{1}$ is expressed as:

$$
V_{O U T}^{\phi_{1}}=V_{I N}+K_{3} V_{B}^{\phi_{1}}=A_{V} V_{I N}-R_{O U T} I_{O U T}
$$

where $K_{3}=\left[\begin{array}{lllll}1 & 1 & \cdots & 1 & 1\end{array}\right]$. From the problem symmetry, this is the same as the output voltage at the end of $\phi_{2}$ (i.e. $V_{O U T}^{\phi_{1}}=V_{O U T}^{\phi_{2}}$ ). The open-circuit voltage gain, $A_{V}$, and the slow switching limit (SSL) output resistance [37], $R_{O U T}$, are obtained from (13) as:

$$
\begin{gathered}
A_{V}=1+K_{3}\left[\left(I-M_{B B}-M_{B A} M_{A B}\right)^{-1} M_{B A} K_{1}\right] \\
R_{O U T}=\frac{\operatorname{sum}\left[\left(I-M_{B A} M_{A B}-M_{B B}\right)^{-1} K_{2}\right]}{2 f_{c l k} C}
\end{gathered}
$$

The open-circuit voltage gain $A_{V}$ is plotted in Fig. 5 versus the number of charge pump stages, $N$, for different values of $\alpha$. The ideal voltage gain for $\alpha=0$ is equal to $N+1$, as expected. As $\alpha$ increases, the open-circuit voltage gain drops due to parasitic capacitors dynamic losses. The dynamic loss increases with the number of stages for a given $\alpha$. It is noted that the open-circuit voltage gain reaches a maximum value as $N$ increases after which the open-circuit voltage starts to decrease slowly (not obvious in Fig. 5 due to scale) as $N$ is increased further.

The normalized SSL output resistance, $R_{O U T_{n}}=$ $2 f_{\text {clk }} C R_{O U T}$, is plotted in Fig. 6. It is noted that the $R_{O U T}$ decreases with $\alpha$ and increases with $N$. The reader should 


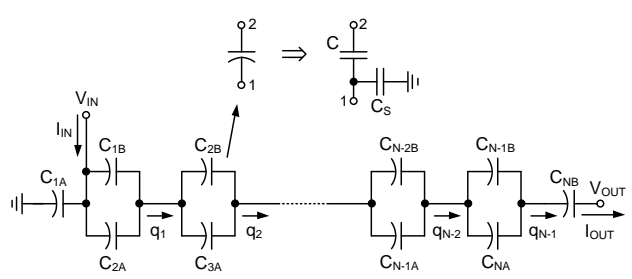

(a)

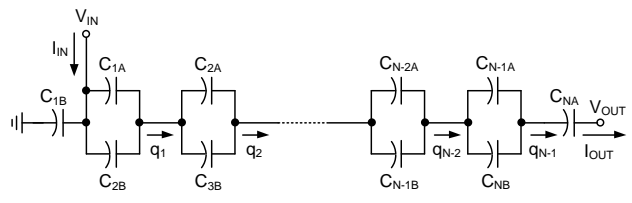

(b)

Figure 4. The pumping capacitors connections in $\phi_{1}$ (a) and $\phi_{2}$ (b)

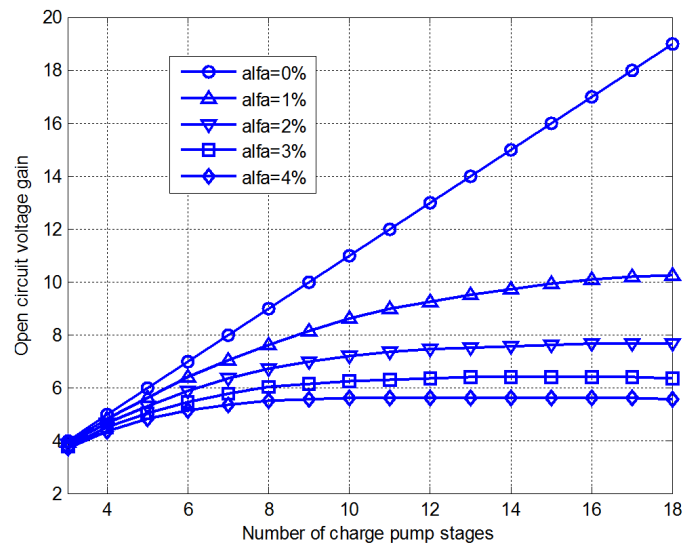

Figure 5. The open-circuit voltage gain versus the number of stages

not be misled by this dependence to conclude that the output voltage would increase for a given load current if we have more parasitics. What happens is that, for a given load current and as $\alpha$ increases, the open-circuit voltage decreases and the output resistance decreases. The net result is a decrease in the actual output voltage. This is verified by plotting the output voltage for $I_{O U T}=1 \mu \mathrm{A}, C=100 \mathrm{pF}$, and $V_{I N}=5 \mathrm{~V}$ as shown in Fig. 6.

To complete the two-port model of the charge pump, we need to find an expression of the input current, $I_{I N}$. From Fig. 4, this current can be expressed as:

$$
\begin{aligned}
I_{I N}= & 2 f_{c l k} C\left[\left(v_{1 A}^{\phi_{1}}-v_{1 A}^{\phi_{2}}\right)-\left(v_{2 A}^{\phi_{1}}-v_{2 A}^{\phi_{2}}\right)-\left(v_{1 B}^{\phi_{1}}-v_{1 B}^{\phi_{2}}\right)\right. \\
& \left.+\alpha V_{I N}+\alpha\left(V_{I N}-v_{2 A}^{\phi_{2}}\right)\right] \\
= & K_{4} V_{A}^{\phi_{1}}+K_{5} V_{B}^{\phi_{1}}+2 \alpha V_{I N}
\end{aligned}
$$

where $K_{4}=\left[\begin{array}{llllll}2 & -1 & 0 & 0 & \cdots & 0\end{array}\right]$ and $K_{5}=$ $\left[\begin{array}{llllll}-2 & 1-\alpha & 0 & 0 & \cdots & 0\end{array}\right]$. Now, by substituting from equations (11) and (13) into (17), we obtain the following expression:

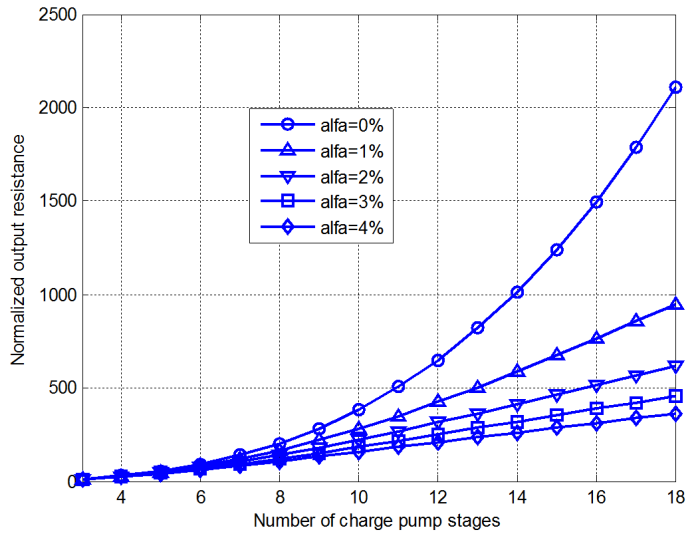

Figure 6. The normalized output resistance versus the number of stages

$$
I_{I N}=Y_{I N} V_{I N}+\beta I_{O U T}
$$

where

$$
\begin{gathered}
Y_{I N}=2 f_{c l k} C\left[\left(K_{4} M_{A B}+K_{5}\right)\left(I-M_{B B}-M_{B A} M_{A B}\right)^{-1}\right. \\
\left.M_{B A} K_{1}+K_{4} K_{1}+2 \alpha\right]
\end{gathered}
$$

and

$$
\beta=-\left(K_{4} M_{A B}+K_{5}\right)\left(I-M_{B B}-M_{B A} M_{A B}\right)^{-1} K_{2}
$$

The power conversion efficiency can be expressed as:

$$
\eta=\frac{I_{O U T}\left(A_{V} V_{I N}-R_{O U T} I_{O U T}\right)}{V_{I N}\left(Y_{I N} V_{I N}+\beta I_{O U T}\right)} \times 100 \%
$$

The power efficiency is plotted versus the load current for $N=10$ in Fig. 7. As a sanity check, the efficiency is expected to be close to $100 \%$ for very small load current (negligible charge transfer losses) at $\alpha=0$ (ideal capacitors). The output voltage ripple can be obtained by finding the high-frequency output capacitance of the charge pump during $\phi_{1}$ or $\phi_{2}$, which can be expressed as:

$$
\begin{gathered}
C_{\text {OUT }}=C_{N}=\frac{C}{1+\frac{1}{\alpha+C_{N-1} / C}} \\
C_{i}=\frac{2 C}{1+\frac{1}{\alpha+C_{i-1} / 2 C}} \text { for } i=2,3, \cdots, N-1
\end{gathered}
$$

where $C_{1}=2 C$. Equations (22-23) can be solved to obtain $C_{O U T}$. The output voltage ripple for a load capacitor $C_{L}$ and an average load current $I_{O U T}$ is expressed as:

$$
\Delta V_{O U T}=\frac{I_{O U T}}{2 f_{c l k}\left(C_{O U T}+C_{L}\right)}
$$

\section{IMPROVED CHARge PUMP}

It is noted from the previous analysis that the open circuit output voltage of the proposed charge pump drops dramatically 


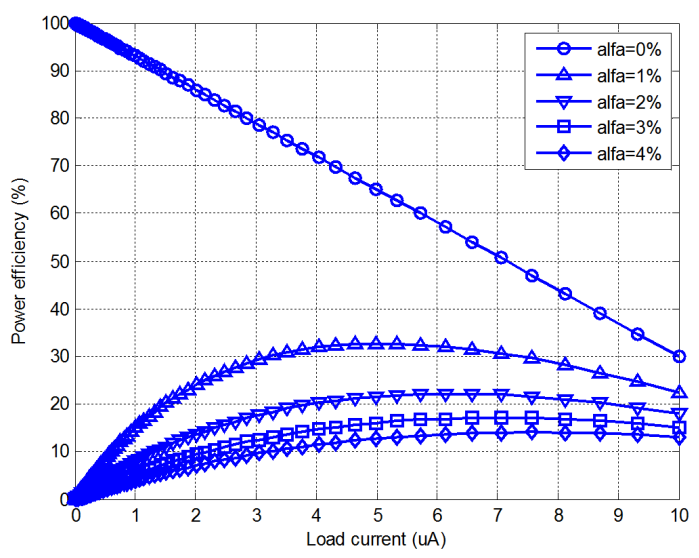

Figure 7. Power efficiency for 10-stage charge pump versus load current

with the presence of the parasitic capacitance from pumping nodes to ground. To explain this effect with some handwaving analysis, lets have a closer look at the pumping capacitors connections in Fig. 4. We note that, for example in $\phi_{1}$, charge sharing occurs between capacitors $C_{i B S}$ and $C_{(i+1) A S}$, for $i=2,3, \cdots, N-1$. Assuming ideal voltage level at the $i^{t h}$ stage, $C_{i B S}$ is charged to $i V_{I N}$ and $C_{(i+1) A S}$ is charged to $(i+2) V_{I N}$ during $\phi_{2}$. After charge sharing in $\phi_{1}, C_{i B S}$ is charged and $C_{(i+1) A S}$ to the same voltage level $(i+1) V_{I N}$. No extra charge is needed in this presumed condition to charge or discharge the parasitic capacitors. However, capacitor $C_{1 B S}$ is discharged to ground during $\phi_{2}$ and is charged to $V_{I N}$ during $\phi_{1}$. The extra charge obviously comes from the input voltage which will affect power efficiency, but should have no effect on open circuit voltage gain. Finally, the capacitor $C_{N B S}$ is ideally charged to $(N-1) V_{I N}$ during $\phi_{2}$ and is charged to $N V_{I N}$ during $\phi_{1}$. The extra charge comes from the output node which results in dramatic degradation in the output voltage. To estimate the amount of this voltage loss, assume the floating capacitance $C=50 \mathrm{pF}$. At a clock frequency of $1 \mathrm{MHz}, 4 \%$ parasitic capacitance, and $V_{I N}=5 \mathrm{~V}$, the average current dissipated by $C_{N A}$ and $C_{N B}$ is $20 \mu A$. For $N=10$, equation (16) gives $R_{O U T}=1.58 \mathrm{M} \Omega$ and the output voltage drops by approximately $31.6 \mathrm{~V}, 57 \%$ from its ideal value of $55 \mathrm{~V}$.

The above qualitative analysis suggests that, in order to prevent degradation of the open circuit voltage gain in the presence of the parasitic capacitance of pumping capacitors, capacitors $C_{N B}$ and $C_{N A}$ (implemented using poly0-poly1 layers) are shielded at the bottom by nwell layer. The shield layer is connected to the clock signal with the same polarity of the capacitor top plate signal [38]. So the shield layer of $C_{N B}$ is connected to the $C L K$ signal while the shield of $C_{N A}$ is connected to the $C L K b$ signal. Fig. 8 shows the improved pumping capacitors connections in $\phi_{1}$ and $\phi_{2}$. Equations (8) and (10), while equation (9) is modified as follows:

$v_{N-1 B}^{\phi_{1}}=v_{N-1 A}^{\phi_{1}}-v_{N A}^{\phi_{1}}-\alpha v_{N-1 B}^{\phi_{1}}+v_{N B}^{\phi_{1}}+\alpha V_{I N}-\frac{I_{O U T}}{2 f_{c l k} C}$

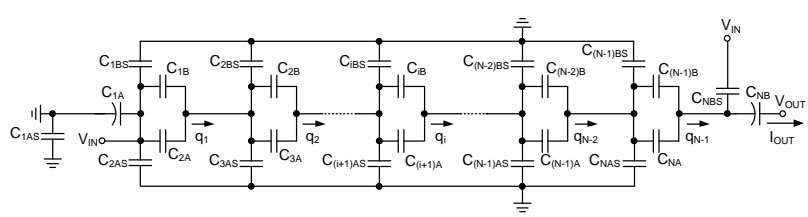

(a)

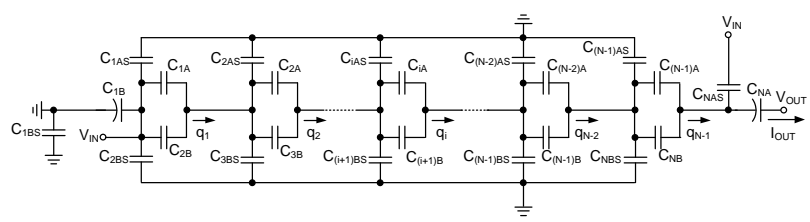

(b)

Figure 8. The pumping capacitors connections in $\phi_{1}$ and $\phi_{2}$

$$
\begin{gathered}
V_{A}^{\phi_{1}}=M_{A B} V_{B}^{\phi_{1}}+K_{1} V_{I N} \\
V_{B}^{\phi_{1}}=\left(I-M_{B B}-M_{B A} M_{A B}\right)^{-1} \\
\left(M_{B A} K_{1} V_{I N}+\alpha K_{2 v} V_{I N}-K_{2} \frac{I_{O U T}}{2 f_{c l k} C}\right)
\end{gathered}
$$

where $K_{2 v}^{T}=\left[\begin{array}{lllll}0 & 0 & \cdots & 0 & 1\end{array}\right]$. Hence, the output voltage becomes:

$$
\begin{gathered}
V_{O U T}^{\phi_{1}}=V_{I N}+K_{3} V_{B}^{\phi_{1}}=A_{V} V_{I N}-R_{O U T} I_{O U T} \\
A_{V-i m p}=1+\left(I-M_{B B}-M_{B A} M_{A B}\right)^{-1} \\
\left(M_{B A} K_{1}+\alpha K_{2 v}\right) \\
R_{O U T-i m p}=\frac{K_{2}}{2 f_{c l k} C}\left(I-M_{B B}-M_{B A} M_{A B}\right)^{-1}
\end{gathered}
$$

While $R_{O U T}$ is unaffected by this modification, $A_{V}$ is significantly improved. Fig. 9 shows the normalized voltage gain of the improved charge pump versus the number of stages. With the assumption that the parasitic capacitances at the pumping nodes are only due to the bottom plate capacitances of the pumping capacitors, the normalized voltage gain in Fig. 9 is equal to the ideal gain in equation (4). However, other parasitic capacitances (e.g. drain, source, and gate capacitances of MOS devices, wiring parasitics, etc...) are not considered in the above equations. If these capacitances are to be considered, voltage gain equation (15) can be used by replacing $\alpha$ with the ratio of the remaining parasitic capacacitances (not including the bottom plate parasitic capacitance of the pumping capacitors) to the value of the pumping capacitors. This modified value of $\alpha$ can be made arbitrarily small by increasing the size of the pumping capacitors with respect to the size of the MOS switches. 


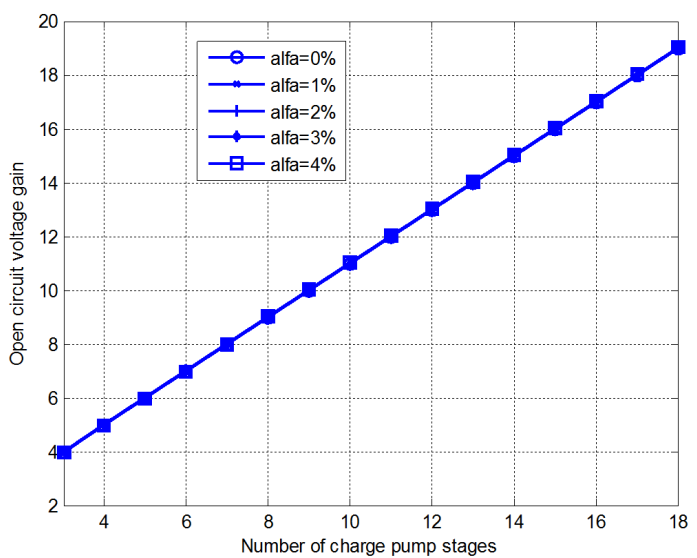

Figure 9. The open-circuit voltage gain of the improved charge pump versus the number of stages

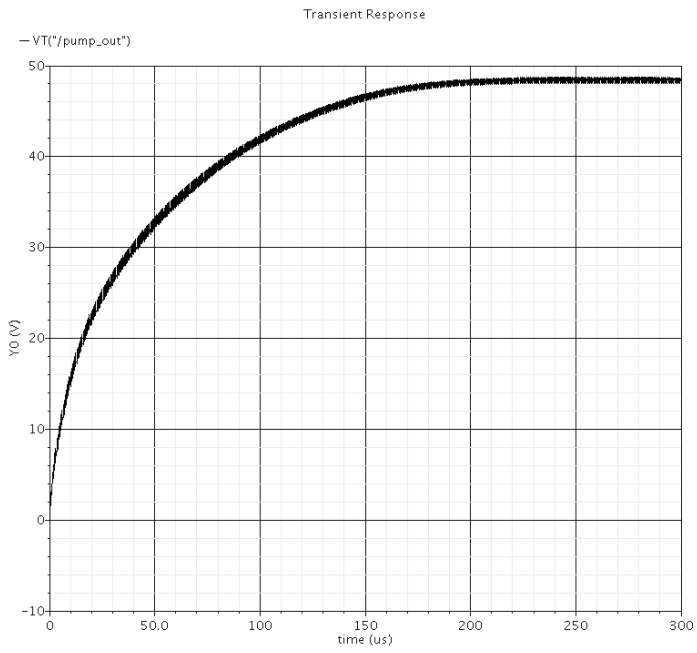

Figure 10. Startup transient of the SCCP-OS for $1 p F$ load capacitor and $50 M \Omega$ load resistor at $V_{I N}=5 \mathrm{~V}$

Startup transient of the SCCP-OS is shown in Fig.

\section{Measurement Results}

The two proposed charge pump circuits (SCCP-DCS and SCCP-OS) based on the improvement suggested in section IV were fabricated in $0.6 \mu \mathrm{m}$ CMOS technology from XFAB. The technology provides high-voltage PMOS transistors with a minimum drain-substrate punch-through voltage of $70 \mathrm{~V}$ and a typical threshold voltage of $-0.97 \mathrm{~V}$. Fig. 11 shows the die photo of the fabricated chip. Areas of the 18-stage SCCPDCS and 14-stage SCCP-OS are $2.42 \mathrm{~mm}^{2}$ and $2.86 \mathrm{~mm}^{2}$, respectively. $50 \mathrm{pF}$ puming capacitors were used for both charge pumps and $10 p F$ capacitors were used for clock level shifters of the SCCP-OS.

First we present the measurement results of the 14-stage SCCP-OS. The first stage of the charge pump is designed with five times large pumping capacitances $(250 \mathrm{pF})$ than following stages in order to drive the rest of the $13^{\text {th }}$ stages, including the clock shifters. The output voltage of versus load current for different values of the input voltage is shown in Fig. 12 for $2 \mathrm{MHz}$ clock frequency. The output voltage reached $42.8 \mathrm{~V}$

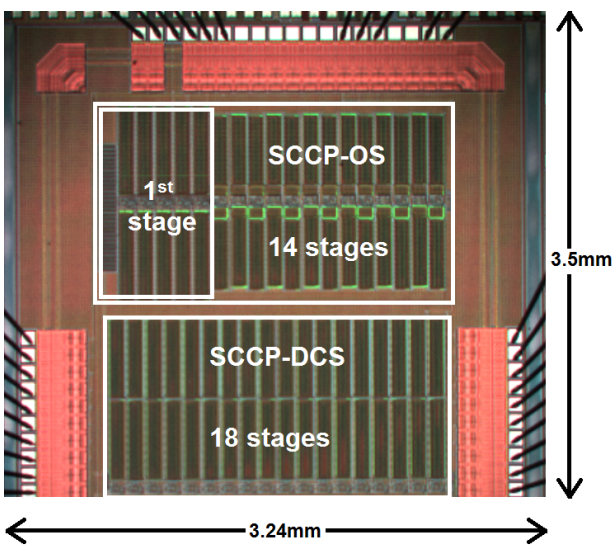

Figure 11. Die photo of the two charge pumps

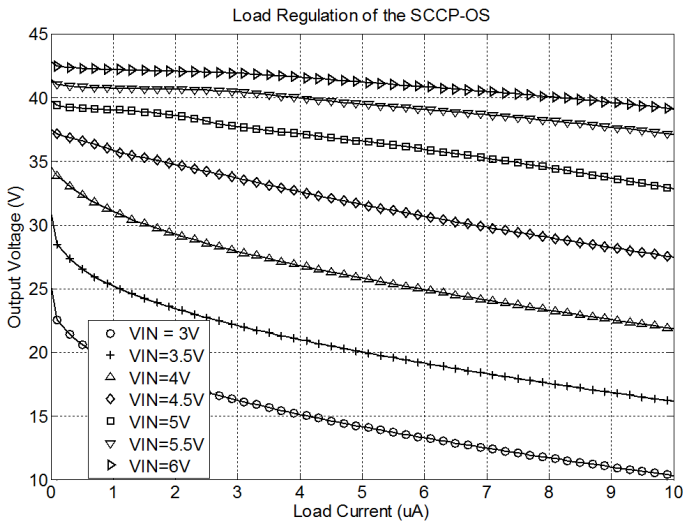

Figure 12. Output voltage of the SCCP-OS versus the load current for different values of the input voltage

when $V_{I N}=6 \mathrm{~V}$ at light loads. According to Fig. 5, this measured open-circuit output voltage suggests that the equivalent parasitic capacitances (excluding capacitances associated with the bottom plate of the pumping capacitors) at the pumping nodes is approximately $3 \%$ of the pumping capacitances. The SSL output resistance is approximately $430 k \Omega$ which results from a total parasitics capacitances $14.5 \%$ (including bottom plate capacitances of the pumping capacitors), according to equation (16).

Fig. 13 shows the output voltage of the SCCP-OS versus the switching frequency at $I_{O U T}=1 \mu \mathrm{A}$ and $V_{I N}=6 \mathrm{~V}$. The output voltage peak voltage occurs at a clock frequency around $2.5 \mathrm{M} \mathrm{Hz}$ while the curve is almost flat from $1.5 \mathrm{M} \mathrm{Hz}$ to $5 \mathrm{MHz}$.

Second, the output voltage of the 18-stage SCCP-DCS is plotted versus the input current for different values of the input voltage in Fig. 14. The clock frequency was set to $500 \mathrm{kHz}$. The peak voltage reached $51 \mathrm{~V}$ at $V_{I N}=6 \mathrm{~V}$. The output voltage is plotted versus the clock frequency in Fig. 15 for $I_{O U T}=1 \mu \mathrm{A}$ and $V_{I N}=6 \mathrm{~V}$. The peak voltage is reach at a clock frequency around $400 \mathrm{kHz}$.

To measure the output ripples of proposed charge pumps, we must not connect the charge pump output directly to the oscilloscope because it will be overloaded with its $1 M \Omega$ input impedance. Instead, the output voltage is attenuated by 


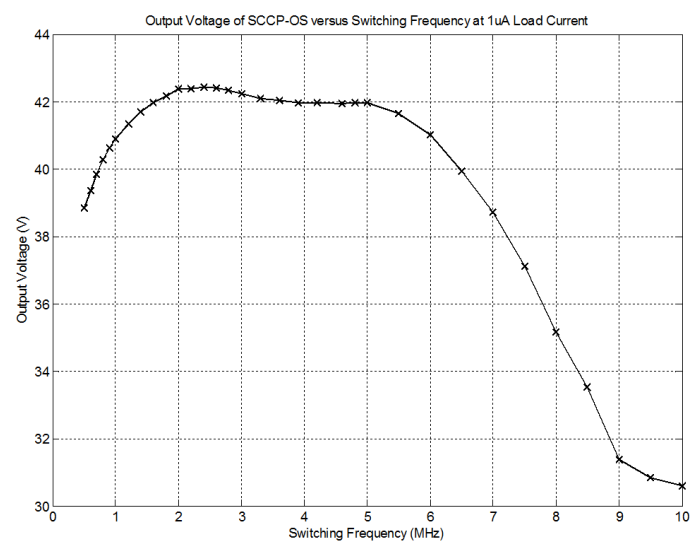

Figure 13. Output voltage of the SCCP-OS versus the switching frequency at $I_{O U T}=1 \mu A$ and $V_{I N}=6 \mathrm{~V}$

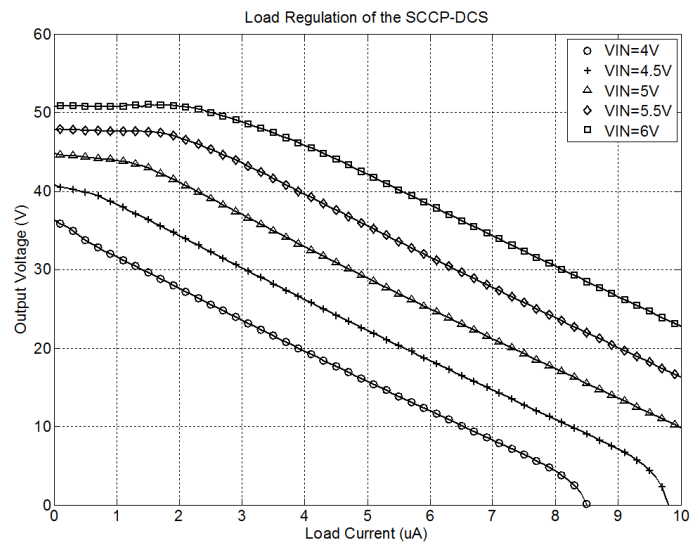

Figure 14. Output voltage of the SCCP-DCS versus the load current for different values of the input voltage

a factor of 5 with a $100 M \Omega$ resistor divider then buffered with an external unity-gain buffer with high input imepdance. The buffer output ripples of the SCCP_OS case is shown in Fig. 16. The ripples peak-peak magnitude is $200 \mathrm{mV}$ which indicates $1 V$ ripples at the SCCP_OS output. The ripples peakto-peak magnitude of the attenuated SCCP_DCS output is $100 \mathrm{mV}$ as shown in Fig. 17, indicating $500 \mathrm{mV}$ ripples at the charge pump output. It is important to note that no smoothing capacitors were used at the output of the charge pumps. If external smoothing capacitors are used, the ripples magnitude will be significantly reduced.

The proposed charge pump is compared with high-voltage charge pumps previously reported in the literature in Table I. It is evident that the proposed architecture offers the highest output voltage in a CMOS technology.

\section{CONCLUSION}

In this work, two high-voltage charge pump circuits has been designed and fabricated. A special clocking scheme has been used to limited the maximum voltage across the pumping capacitors and hence allow using low-voltage capacitor. The two charge pumps were fabricated in XFAB $0.6 \mu \mathrm{m}$ CMOS technology. Measurements shows that the two charge pumps

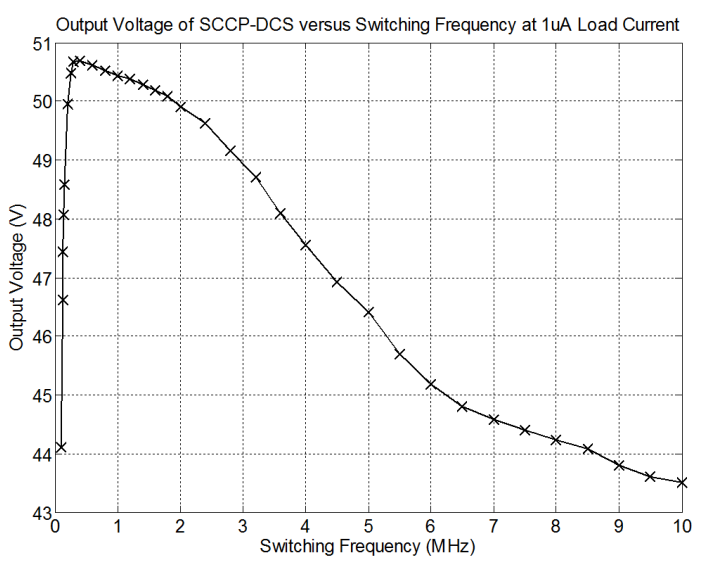

Figure 15. Output voltage of the SCCP-DCS versus the switching frequency at $I_{O U T}=1 \mu A$ and $V_{I N}=6 \mathrm{~V}$

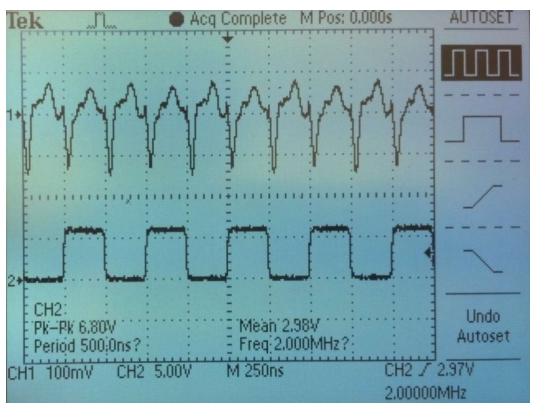

Figure 16. Output ripple voltage in SCCP_OS

generated $42.8 \mathrm{~V}$ and $51 \mathrm{~V}$ outputs while keeping the maximum voltage across pumping capacitors below $6 \mathrm{~V}$. Compared to high-voltage charge pumps in the literature, these two charge pumps generate the highest output voltages.

\section{REFERENCES}

[1] M. AbdElFattah, A. Mohieldin, A. Emira, and E. Sanchez-Sinencio, "A low-voltage charge pump for micro scale thermal energy harvesting," in Industrial Electronics (ISIE), 2011 IEEE International Symposium on, june 2011, pp. $76-80$.

[2] S. Abdelaziz, A. Emira, A. Radwan, A. Mohieldin, and A. Soliman, "A low start up voltage charge pump for thermoelectric energy scavenging," in Industrial Electronics (ISIE), 2011 IEEE International Symposium on, june 2011, pp. $71-75$.

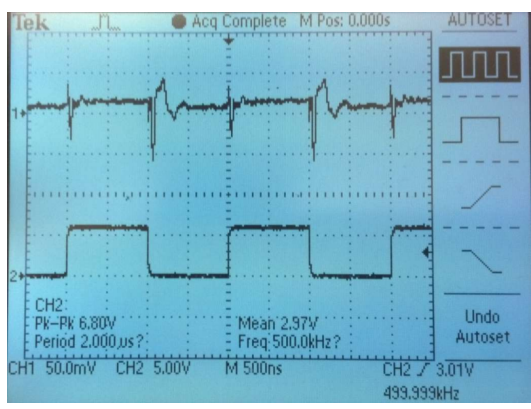

Figure 17. Output ripple voltage in SCCP_DCS 
Table I

COMPARISON TABLE

\begin{tabular}{|c|c|c|c|c|c|c|c|c|c|}
\hline Reference & $\begin{array}{c}\text { Max. } \\
V_{O U T}{ }^{a} \\
\end{array}$ & $\mathbf{N}^{b}$ & $\begin{array}{l}\text { Supply } \\
\text { Voltage }\end{array}$ & $\begin{array}{c}\text { Load } \\
\text { current }\end{array}$ & Technology & $\begin{array}{l}\text { Switching } \\
\text { frequency }\end{array}$ & $\begin{array}{l}\text { Pumping } \\
\text { capacitor }\end{array}$ & $\begin{array}{l}\text { Max. cap. } \\
\text { voltage }^{d}\end{array}$ & $\begin{array}{l}\text { Active } \\
\text { devices }\end{array}$ \\
\hline SCCP-OS & $42.8 \mathrm{~V}$ & 14 & $6 \mathrm{~V}$ & $\begin{array}{ll} & 10 \mu \mathrm{A} \\
\text { @ } & 10 \% \text { drop }\end{array}$ & $0.6 \mu \mathrm{m}$ CMOS & $2 M H z$ & $50 p F$ & $6 \mathrm{~V}$ & $\begin{array}{l}\text { PMOS } \\
\text { only }^{e}\end{array}$ \\
\hline SCCP-DCS & 51 & 18 & $6 \mathrm{~V}$ & $\begin{array}{c}4 \mu \mathrm{A} \\
\text { @ } 10 \% \text { drop }\end{array}$ & $0.6 \mu \mathrm{m}$ CMOS & $500 k H z$ & $50 p F$ & $6 \mathrm{~V}$ & $\begin{array}{c}\text { PMOS } \\
\text { only }\end{array}$ \\
\hline [25] & 19.6 & 6 & $3.3 \mathrm{~V}$ & $20 \mu A$ & $\begin{array}{c}0.35 \mu \mathrm{m} \text { SOI } \\
\text { CMOS }\end{array}$ & $4 M H z$ & $16 p F$ & $16.3 \mathrm{~V}$ & $\begin{array}{c}\text { Diodes } \\
\text { only }\end{array}$ \\
\hline [26] & 26.9 & 9 & $3.3 \mathrm{~V}$ & $40 \mu A$ & $\begin{array}{l}0.35 \mu \mathrm{m} \text { SOI } \\
\text { CMOS }\end{array}$ & $4 M H z$ & $30 p F$ & $23.6 \mathrm{~V}$ & $\begin{array}{l}\text { PMOS- } \\
\text { NMOS }\end{array}$ \\
\hline$[19]^{c}$ & 39 & 3 & $5 V$ & $2 m A$ & $\begin{array}{l}0.7 \mu \mathrm{m}-100 \mathrm{~V} \\
\text { CMOS }\end{array}$ & $1 M H z$ & $\begin{array}{c}\text { Not } \\
\text { specified }\end{array}$ & $39 \mathrm{~V}$ & $\begin{array}{l}\text { PMOS- } \\
\text { NMOS }\end{array}$ \\
\hline [18] & 8.7 & 4 & $2.5 \mathrm{~V}$ & $360 \mu A$ & $0.13 \mu \mathrm{m} \mathrm{CMOS}$ & $20 M H z$ & $37 p F$ & $6.3 \mathrm{~V}$ & $\begin{array}{c}\text { NMOS } \\
\text { only }\end{array}$ \\
\hline [31] & 14.8 & 10 & $1.8 \mathrm{~V}$ & $0.7 \mu A$ & $0.18 \mu \mathrm{m} \mathrm{CMOS}$ & $50 \mathrm{MHz}$ & $10 p F$ & $13 \mathrm{~V}$ & $\begin{array}{l}\text { PMOS- } \\
\text { NMOS }\end{array}$ \\
\hline [33] & 28 & 12 & $2.5 \mathrm{~V}$ & $\begin{array}{c}2 \mu \mathrm{A} \\
\text { @ } 20 \% \text { drop }\end{array}$ & $\begin{array}{c}0.25 \mu \mathrm{m} \text { CMOS } \\
\text { w/ polySi diodes }\end{array}$ & $1 M H z$ & $\begin{array}{c}\text { Not } \\
\text { specified }\end{array}$ & $25.5 \mathrm{~V}$ & $\begin{array}{c}\text { Diodes } \\
\text { only }\end{array}$ \\
\hline
\end{tabular}

${ }^{a}$ It may be noticed that the number of stages in the proposed charge pumps is higher than others. This is attributed to the chosen series-capacitor topology which increases the charge pump sensitivity to parasitic capacitors. The use of poly0-poly1 pumping capacitors resulted in even higher parasitics due to their proximity to the substrate.

$b$ The proposed charge pumps offers the highest output voltage using CMOS technology compared to other charge pumps proposed in the literature.

${ }^{c}$ This reference has only simulation results. Exponential charge pump architecture is used.

$d$ Maximum voltage across pumping capacitors is $V_{O U T}-V_{I N}$ in most cases, except for the proposed designs and in [19].

$e^{e}$ Except for the first stage clock level shifting circuit where NMOS transistors are used.

[3] A. Umezawa, S. Atsumi, M. Kuriyama, H. Banba, K. Imamiya, K. Naruke, S. Yamada, E. Obi, M. Oshikiri, T. Suzuki, and S. Tanaka, "A 5-V-only operation 0.6- $\mu \mathrm{m}$ flash EEPROM with row decoder scheme in triple-well structure," Solid-State Circuits, IEEE Journal of, vol. 27, no. 11, pp. 1540 -1546, nov 1992.

[4] J. Shin, I.-Y. Chung, Y. J. Park, and H. S. Min, “A new charge pump without degradation in threshold voltage due to body effect [memory applications]," Solid-State Circuits, IEEE Journal of, vol. 35, no. 8, pp. 1227 1230, aug. 2000.

[5] S. Atsumi, M. Kuriyama, A. Umezawa, H. Banba, K. Naruke, S. Yamada, Y. Ohshima, M. Oshikiri, Y. Hiura, T. Yamane, and K. Yoshikawa, "A 16-Mb flash EEPROM with a new self-data-refresh scheme for a sector erase operation," Solid-State Circuits, IEEE Journal of, vol. 29, no. 4, pp. 461 -469, apr 1994.

[6] T. Tanzawa, T. Tanaka, K. Takeuchi, and H. Nakamura, "Circuit techniques for a 1.8-V-only NAND flash memory," Solid-State Circuits, IEEE Journal of, vol. 37, no. 1, pp. $84-89$, jan 2002.

[7] T. Ishii, K. Oshima, H. Sato, S. Noda, J. Kishimoto, H. Kotani, A. Nozoe, K. Furusawa, T. Yoshitake, M. Kato, M. Takahashi, A. Sato, S. Kubono, K. Manita, K. Koda, T. Nakayama, and A. Hosogane, "A 126.6- $\mathrm{mm}^{2}$ AND-type 512-Mb flash memory with
1.8-V power supply," Solid-State Circuits, IEEE Journal of, vol. 36, no. 11, pp. 1707 -1712, nov 2001.

[8] A. Richelli, L. Colalongo, L. Mensi, A. Cacciatori, and Z. Kovacs-Vajna, "Charge pump architectures based on dynamic gate control of the pass-transistors," Very Large Scale Integration (VLSI) Systems, IEEE Transactions on, vol. 17 , no. 7, pp. $964-967$, july 2009.

[9] R. Gariboldi and F. Pulvirenti, "A $70 \mathrm{~m} \Omega$ intelligent high side switch with full diagnostics," Solid-State Circuits, IEEE Journal of, vol. 31, no. 7, pp. 915 -923, jul 1996.

[10] — , "A monolithic quad line driver for industrial applications," Solid-State Circuits, IEEE Journal of, vol. 29, no. 8, pp. 957 -962, Aug 1994.

[11] K. Hwu and Y. Yau, "Voltage-boosting converter based on charge pump and coupling inductor with passive voltage clamping," Industrial Electronics, IEEE Transactions on, vol. 57, no. 5, pp. 1719 -1727, may 2010.

[12] M. van Wesenbeeck, J. Klaasens, U. von Stockhausen, A. Munoz de Morales Anciola, and S. Valtchev, "A multiple-switch high-voltage DC-DC converter," Industrial Electronics, IEEE Transactions on, vol. 44, no. 6, pp. $780-787$, dec 1997.

[13] L.-S. Yang, T.-J. Liang, and J.-F. Chen, "Transformerless DC-DC converters with high step-up voltage gain," Industrial Electronics, IEEE Transactions on, vol. 56, no. 8, pp. $3144-3152$, aug. 2009. 
[14] C.-T. Pan and C.-M. Lai, "A high-efficiency high stepup converter with low switch voltage stress for fuelcell system applications," Industrial Electronics, IEEE Transactions on, vol. 57, no. 6, pp. 1998 -2006, june 2010.

[15] T. Liang, J. lee, S. Chen, J. Chen, and L. Yang, "Novel Isolated High-step-up DC-DC Converter with Voltage Lift," Industrial Electronics, IEEE Transactions on, vol. PP, no. 99, p. 1, 2011.

[16] L.-S. Yang, T.-J. Liang, H.-C. Lee, and J.-F. Chen, "Novel high step-up DC-DC converter with coupledinductor and voltage-doubler circuits," Industrial Electronics, IEEE Transactions on, vol. 58, no. 9, pp. 4196 -4206, sept. 2011.

[17] C. Young, M. Chen, T. Chang, C. Ko, and K. Jen, "Cascade Cockcroft-Walton Voltage Multiplier Applied to Transformerless High Step-up DC-DC Converter," Industrial Electronics, IEEE Transactions on, vol. PP, no. 99, p. 1, 2012.

[18] O. Khouri, S. Gregori, A. Cabrini, R. Micheloni, and G. Torelli, "Improved charge pump for flash memory applications in triple well CMOS technology," in Industrial Electronics, 2002. ISIE 2002. Proceedings of the 2002 IEEE International Symposium on, vol. 4, 2002, pp. $1322-1326$ vol.4.

[19] R. Casanova, P. Miribel-Catala, A. Saiz, M. Puig-Vidal, and J. Samitier, "Design of a step-up $400 \mathrm{mW@40}$ $\mathrm{V}$ charge-pump for microrobotics applications in a 100 $\mathrm{V}-0.7 \mu \mathrm{m}$ intelligent interface technology," in Industrial Electronics, 2004 IEEE International Symposium on, vol. 2, may 2004, pp. $1227-1229$ vol. 2.

[20] G. Palumbo and D. Pappalardo, "Charge pump circuits: an overview on design strategies and topologies," Circuits and Systems Magazine, IEEE, vol. 10, no. 1, pp. $31-45$, quarter 2010.

[21] J. Dickson, "On-chip high-voltage generation in MNOS integrated circuits using an improved voltage multiplier technique," Solid-State Circuits, IEEE Journal of, vol. 11, no. 3, pp. 374 - 378, Jun. 1976.

[22] J. Cockcroft and E. Walton, "Production of high velocity positive ions," Proceedings of the Royal Society, vol. 136, pp. 619-630, 1932.

[23] J. Pan and T. Yoshihara, "A charge pump circuit without overstress in low-voltage CMOS standard process," in Electron Devices and Solid-State Circuits, 2007. EDSSC 2007. IEEE Conference on, 2007, pp. 501 -504.

[24] X. Wang, D. Wu, F. Qiao, P. Zhu, K. Li, L. Pan, and R. Zhou, "A high efficiency CMOS charge pump for low voltage operation," in ASIC, 2009. ASICON '09. IEEE 8th International Conference on, 2009, pp. 320 -323.

[25] M. Hoque, T. McNutt, J. Zhang, A. Mantooth, and M. Mojarradi, "A high voltage Dickson charge pump in SOI CMOS," in Custom Integrated Circuits Conference, 2003. Proceedings of the IEEE 2003, 2003, pp. 493 496.

[26] M. Hoque, T. Ahmad, T. McNutt, A. Mantooth, and M. Mojarradi, "Design technique of an on-chip, highvoltage charge pump in SOI," in Circuits and Systems,
2005. ISCAS 2005. IEEE International Symposium on, May 2005, pp. 133 - 136 Vol. 1.

[27] T. Ying, W.-H. Ki, and M. Chan, "Area-efficient CMOS charge pumps for LCD drivers," Solid-State Circuits, IEEE Journal of, vol. 38, no. 10, pp. 1721 - 1725, oct. 2003.

[28] W. C. Huang, J. C. Cheng, and P. C. Liou, "A charge pump circuit - cascading high-voltage clock generator," in Electronic Design, Test and Applications, 2008. DELTA 2008. 4th IEEE International Symposium on, 2008, pp. $332-337$.

[29] J.-F. Richard and Y. Savaria, "High voltage charge pump using standard CMOS technology," in Circuits and Systems, 2004. NEWCAS 2004. The 2nd Annual IEEE Northeast Workshop on, 2004, pp. 317 - 320.

[30] M. Nozaki, W. Tangsrirar, Y. Suzuki, M. Yoshid, S. Saitoh, M. Teramoto, and A. Yamaguchi, "New double charge-pumping circuit for high-voltage generation," in Circuits and Systems, 1998. IEEE APCCAS 1998. The 1998 IEEE Asia-Pacific Conference on, Nov. 1998, pp. $719-722$.

[31] M. Innocent, P. Wambacq, S. Donnay, W. Sansen, and H. De Man, "A linear high voltage charge pump for MEMs applications in $0.18 \mu \mathrm{m}$ CMOS technology," in Solid-State Circuits Conference, 2003. ESSCIRC '03. Proceedings of the 29th European, sept. 2003, pp. 457 460.

[32] M.-D. Ker, S.-L. Chen, and C.-S. Tsai, "Design of charge pump circuit with consideration of gate-oxide reliability in low-voltage CMOS processes," Solid-State Circuits, IEEE Journal of, vol. 41, no. 5, pp. 1100 - 1107, may 2006.

[33] M.-D. Ker and S.-L. Chen, "On-Chip High-Voltage Charge Pump Circuit in Standard CMOS Processes With Polysilicon Diodes," in Asian Solid-State Circuits Conference, 2005.

[34] R. Antonello, R. Oboe, L. Prandi, and F. Biganzoli, "Automatic mode matching in MEMS vibrating gyroscopes using extremum-seeking control," Industrial Electronics, IEEE Transactions on, vol. 56, no. 10, pp. $3880-3891$, 2009.

[35] A. Sharma, M. Zaman, and F. Ayazi, "A sub-0.2 hr bias drift micromechanical silicon gyroscope with automatic CMOS mode-matching," Solid-State Circuits, IEEE Journal of, vol. 44, no. 5, pp. 1593 -1608, May 2009.

[36] G. DiCataldo and G. Palumbo, "Design of an Nth order Dickson voltage multiplier," Circuits and Systems I: Fundamental Theory and Applications, IEEE Transactions on, vol. 43, no. 5, p. 414, may 1996.

[37] M. Seeman and S. Sanders, "Analysis and optimization of switched-capacitor DC-DC converters," Power Electronics, IEEE Transactions on, vol. 23, no. 2, pp. 841 -851 , march 2008.

[38] L. Mensi, L. Colalongo, A. Richelli, and Z.-M. KovacsVajna, "A new integrated charge pump architecture using dynamic biasing of pass transistors," in Solid-State Circuits Conference, 2005. ESSCIRC 2005. Proceedings of the 31st European, sept. 2005, pp. $85-88$. 


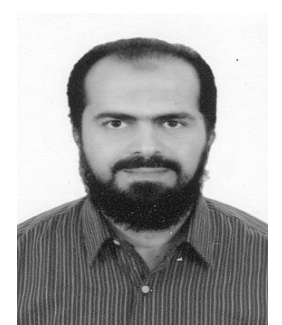

A hmed Emira (S'00-M'05-SM'09) received the B.Sc. and M.Sc. degrees in electronics and communications from Cairo University, Giza, Egypt, in 1997 and 1999, respectively, and the Ph.D. degree in electrical engineering from Texas A\&M University, College Station, in 2003. From 2001 to 2002, he was an intern with Motorola, Austin, TX, where he worked as an RFIC Design Engineer. From 2003 to 2006, following his Ph.D. degree, he was an RFIC Design Engineer with the Wireless Division, Silicon Laboratories, Austin. From 2006 to 2008, he worked as a Senior RFIC Design Engineer and a Leader for the Power Management Team, Newport Media Inc., Lake Forest, CA. Since 2007, he has been working as an Assistant Professor at the Electronics and Communications Department, Cairo University. He is also leading the RFIC team at Newport Media Inc., Egypt Design Center, since February 2012. Dr. Emira has authored or coauthored more than 35 journal and conference publications and is the holder of five issued U.S. patents with several pending. His current interests include low-power mixed-signal circuits for portable devices/energy harvesting systems, RF circuits, microelectromechanical systems interface electronics, and wireless communication systems architectures. Dr. Emira was awarded the Motorola Scholarship in 2000. He was the recipient of the Third Best Student Paper Award at the IEEE RFIC, Seattle, WA, in 2002.

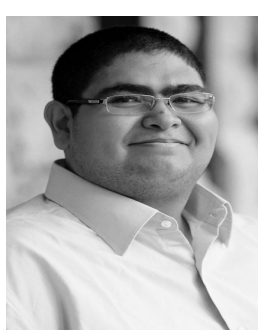

M ohamed AbdelGhany received the B.S. and M.S. degrees in Electronics and Electrical Communications engineering from Cairo University in 2009 and 2011 respectively. He is currently a Ph.D. student in Electrical Engineering at McGill University.

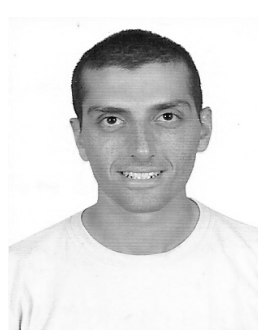

M r. Mohannad Elsayed was born in Cairo, Egypt in 1985. He received his B.Sc. and M.Sc. degrees in Electronics and Communications Engineering from Cairo University, Egypt in 2007 and 2010, respectively. He is currently a Ph.D. student at the MEMS and Wireless Integrated Circuits Laboratory, McGill University, Canada. From 2007 to 2010, Mr. Elsayed worked as a teaching assistant at the Electronics and Communications Engineering Department, Cairo University, Egypt, and a research assistant at Yousef Jameel Science and Technology Research Center, The American University in Cairo, Egypt. He has held internship positions in several places including Rice Automated Nanoscale Design Laboratory, Rice University, USA, and Thales, Canada. Mr. Elsayed authored and co-authored 7 journal and conference papers. His research interests include MEMS devices, and analog circuits.

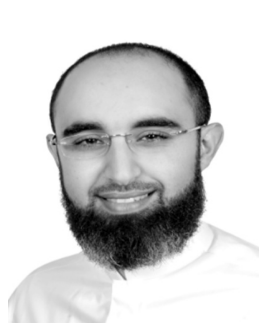

A mro M. Elshurafa (S'01-GSM'02-M'09) received his BEng (with distinction), MASc, and $\mathrm{PhD}$ degrees all in electrical engineering from Dalhousie University, Halifax, Nova Scotia, Canada, in 2002, 2005, and 2009 respectively. In 2009, he joined King Abdullah University of Science and Technology (KAUST), Thuwal, Saudi Arabia, as a post doctoral fellow where he still remains. He spent his first year of appointment with KAUST in a secondment at the American University in Cairo, under the auspices of the KAUST Global Collaborative Research Partnership Program. His research interests include design, multi-physics finite element modeling, fabrication, and characterization of RF MEMS devices and circuits, MEMS inertial sensors, MEMS piezoelectric energy scavengers, and MEMS control and interface circuits. Dr. Elshurafa is a certified internal quality auditor (certified by ISO), a certified six sigma black-belter, a certified safety officer, and a registered professional engineer (PEng) in the province of Nova Scotia, Canada. Dr. Elshurafa was the winner of the prestigious Canadian Network of Centers of Excellence on Microelectronics (Micronet) Scholarship which is funded by the federal government and industry of Canada.

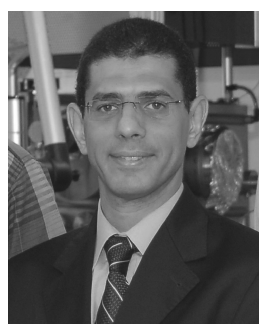

S herif Sedky was born in Cairo (Egypt) in 1969. He received the B.Sc. degree, with honors, in electronics engineering in 1992, and the M.Sc. degree in engineering physics in 1995 both from Faculty of Engineering, Cairo University, and the Ph.D. degree in microelectronics in 1998 from the KatholiekeUniversiteit Leuven, Belgium. In 1995 he joined the MEMS group of the Interuniversity Microelectronics Center (IMEC) in Leuven (Belgium). During the academic year 1999-2000, he was a postdoctoral fellow at the Katholieke Universiteit Leuven, and a visiting professor at the same university during Summer 2001, 2003, 2004, 2005, 2006, 2007 and 2008. In 2002 he was a visiting researcher at the University of California, Berkeley. In February 2004 he has been promoted to associate professor and o full professor in 2008. He served as the director of Yousef Jameel Science and Technology Research Center, and associate dean for graduate studies and research at The American University in Cairo. Currently he is the founding provost of Zewail University. He is a member in the Institute of Electrical and Electronic Engineers (IEEE). He holds eight patents and authored and coauthored over ninety international publications and a book chapter in the field of design, fabrication and monolithic integration of MEMS with the driving electronics using polycrystalline silicon germanium as a structural material. He is the author of the book titled: "Post-processing techniques for integrated MEMS". He established a MEMS fabrication facility at The Science and Technology Research Center at The American University in Cairo. He is a recipient of the 2007 Excellence in research and creative endeavors award. He is also a recipient of the Egyptian prestigious national award in advanced technological sciences in 2002, and the graduate studies award from Cairo University in 1996. He served on the scientific committees of several international conferences.

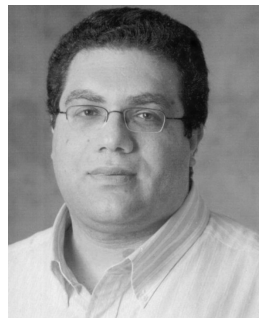

D r. Khaled Salama received his Bachelor's degree with honors from the Electronics and Communications Department at Cairo University in Egypt in 1997, and his Master's and Doctorate degrees from the Electrical Engineering Department at Stanford University in the United States, in 2000 and 2005 respectively. He was an assistant Professor at RPI between 2005 and 2009. He joined King Abdullah University of Science and Technology (KAUST) in January 2009 and is the founding Electrical Engineering program chair. His work on CMOS sensors for molecular detection has been funded by the National Institutes of Health (NIH) and the Defense Advanced Research Projects Agency (DARPA), awarded the Stanford-Berkeley Innovators Challenge Award in biological sciences and was acquired by Lumina Inc. He is the author of 100 papers and 8 patents on low-power mixed-signal circuits for intelligent fully integrated sensors and nonlinear electronics specially memristor devices. He is a senior member of IEEE. 